\title{
Some effects of dietary dextrose, fructose, liquid glucose and sucrose in the adult male rat
}

\author{
By R. J. L. ALLEN \\ Beecham Food and Drink Division, Brentford, Middlesex \\ AND J. S. LEAHY \\ Huntingdon Research Centre, Huntingdon \\ (Received 7 September I965-Accepted 8 December 1965 )
}

\begin{abstract}
I. For 26 weeks, adult male rats were fed on diets containing about $80 \%$ of carbohydrate, given as dextrose, fructose, liquid glucose, or sucrose; their performance was compared with that of rats receiving a standard laboratory cubed diet (4I B) containing $60 \%$ of carbohydrate, mainly as starch. 2. More of diet 4I B was eaten than of any of the diets containing sugars, but only with dextrose was the mean body-weight gain significantly lower than with diet 4I $B$. 3. No significant differences in body length or girth were produced by the different diets. 4 . Compared with those of rats given diet $4 \mathbf{I} \mathrm{B}$, plasma cholesterol levels were significantly increased by fructose and sucrose and to a lesser extent by dextrose, but not by liquid glucose. 5. Compared with those given diet $4 \mathrm{I} \mathrm{B}$, the rats given fructose had heavier hearts, kidneys and livers, those given sucrose had heavier hearts and livers, and those given dextrose had heavier hearts. Those given fructose had the heaviest kidneys and livers, and heavier hearts than those given liquid glucose. The organ weights of those given liquid glucose and those given diet $4 \mathrm{r} B$ were not significantly different. 6 . Compared with the values on diet $4 \mathrm{I} B$, carcass and liver fat were both significantly increased by sucrose and fructose but not by dextrose or liquid glucose. With fructose, liver fat was almost double that with dextrose or liquid glucose. 7. Dry-matter contents of whole carcass and liver followed substantially the same pattern as did the fat contents. 8 . Liver protein content was significantly lower on the $80 \%$ carbohydrate diets. The reductions were greatest with fructose and sucrose.
\end{abstract}

Many workers, of whom those mentioned below are examples, have studied the influence of individual carbohydrates on growth (Monson, Dietrich \& Elvehjem, I95०; Harper \& Katayama, I953), on the utilization of other dietary components (Mitchell, Hamilton \& Beadles, I937; Chang, 1962) and on body composition (Feyder, r935; Bachmann, Haldi, Wynn \& Ensor, 1938; Marshall \& Womak, r954; Macdonald, 1962 $b, 1963$; Macdonald \& Braithwaite, 1964; Carroll, 1964) and there is now a substantial body of evidence that in a number of ways different kinds of dietary carbohydrate do produce different effects in both animals and man.

Preliminary experiments (Allen \& Leahy, unpublished) had shown minor betweentreatment differences in carcass and liver composition of male and female weanling and mature rats fed on diets containing $60 \%$ of dextrose (D-glucose), liquid glucose or sucrose. To emphasize these differences, further experiments, the results of which are now reported, were undertaken in which the carbohydrates studied formed about $80 \%$ of the diet of adult male rats. At the same time the scope of the investigation was extended by including fructose as a fourth sugar, and rats in a fifth group were fed on a standard laboratory diet for comparison. The effects of these diets on body-weight, carcass dimensions, plasma cholesterol level, organ weights and carcass and liver composition were compared. 


\section{EXPERIMENTAL}

Animals and diets. One hundred adult male rats, II months old, of a Medical Research Council Wistar-derived strain which had been maintained on a standard laboratory diet (diet 4I B; see p. 34I) were randomly allocated to five treatment groups so that each group contained twenty rats of similar mean initial weight. Each treatment group was further divided into four subgroups of five rats and each subgroup was housed in one cage, the cages being randomly arranged within the battery. The percentage compositions of the four experimental diets are shown in Table $\mathrm{I}$.

Table I. Percentage compositions of the four experimental diets

$\quad$ Treatment no....
Diet component...
Dextrose (anhydrous)
Fructose
Spray-dried liquid glucose
Sucrose
Casein, light white soluble*
DL-methionine
Arachis oil BP
Powdered cellulose $\dagger$
Mineral mixture*
Vitamin B mixture $\downarrow$
Vitamins A, D, E and $\mathbf{B}_{\mathbf{1 2}}$

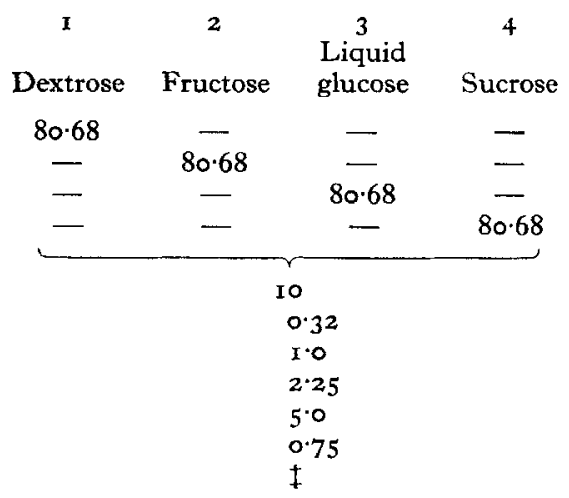

* British Drug Houses Ltd. EC 4

† Solka Floc Grade BW Ioo; Johnson, Jorgenson \& Wettre and Co., 26 Old Bailey, London, t For composition see p. 341 .

Anhydrous dextrose BP having a heat of combustion ((USA) National Research Council, 1929) of $374 \mathrm{kcal} / \mathrm{I} 00 \mathrm{~g}$, sucrose BP (394 kcal/100 g) and $\mathrm{D}(-)$ fructose (British Drug Houses Ltd) (375 kcal/roo g) were used.

Liquid glucose is an aqueous preparation of partially hydrolysed starch (British Pharmaceutical Codex, 1963 ). It consists of a mixture of dextrose, maltose and glucosyl oligosaccharides, and on complete hydrolysis yields only dextrose. Spraydried liquid glucose was used because it was much easier to incorporate into the experimental diets than was the original liquid glucose. It was prepared from liquid glucose of density $4 \mathrm{I}^{\circ}$ Beaumé $(76.5 \%$ carbohydrate) and with a dextrose equivalent (g reducing sugars expressed as dextrose/100 $\mathrm{g}$ dry weight) of 42.5 (Corson, 1957). The heat of combustion as determined in a bomb calorimeter was $395 \mathrm{kcal} / \mathrm{lo0} \mathrm{g}$. The water content was $2 \mathrm{~g} / 100 \mathrm{~g}$. It contained (g/100 g) dextrose 18.7 , maltose 13.9 , maltotriose II 2 , maltotetraose $9 \cdot 8$, higher oligosaccharides 44.4 . Chromatography and determination of the reducing power showed that the carbohydrates in the liquid glucose had not been affected by drying. To provide evidence that the physiological properties of the spray-dried product were also unaltered, the mean absorption rate was compared with that of $0.5 \%$ (w/v on anhydrous sugar content) undried liquid 
glucose in a perfused isolated intestinal segment by the method of Fisher \& Parsons (1949). The results (means of duplicates $\pm \mathrm{SE}$ ), expressed as $\mathrm{mg}$ carbohydrate $/ \mathrm{cm}$ after perfusion for $\mathrm{I} \mathrm{h}$ at $37^{\circ}$ in $50 \mathrm{ml}$ of oxygenated $\left(95 \% \mathrm{O}_{2}, 5 \% \mathrm{CO}_{2}\right)$ KrebsRinger bicarbonate buffer at $\mathrm{pH}_{7 \cdot 2}$, showed a disappearance from the lumen of $\mathrm{I} \cdot 98 \pm 0.05$ for undried liquid glucose and of $2 \cdot 00 \pm 0.03$ for spray-dried liquid glucose. The corresponding amount appearing on the serosal side was $0.96 \pm 0.04$ for undried liquid glucose and $\mathrm{x} \cdot 00 \pm 0.05$ for spray-dried liquid glucose.

Methionine was included because it seemed possible that protein quality might otherwise be a limiting factor in diets formulated to contain as much carbohydrate as possible.

The vitamin B mixture used was that described by Greenberg, Calbert, Savage \& Deuel (1950), except that the choline content was reduced by half and the mixture, thus modified, was included at twice the level recommended by these authors. Preliminary tests had shown greatly increased vitamin B group requirements by rats fed on diets containing $80 \%$ carbohydrate, the effects being particularly pronounced with dextrose. Other vitamins were included in the amounts $/ \mathrm{kg}$ diet: A, 3000 i.u.; D, 1000 i.u.; E, $50 \mathrm{mg} ; \mathrm{B}_{12}, 30 \mu \mathrm{g}$.

The fifth treatment group was given (that is, continued on) the diet on which all the rats had previously been maintained. This was cubed diet $4 \mathrm{I} \mathrm{B}$, a standard laboratory diet prepared according to the formula of Bruce \& Parkes (1949, 1956); it contained $45 \%$ wholemeal flour, $40 \%$ finely-ground oats, $8 \%$ white-fish meal, $3 \%$ dried skim milk, $\mathrm{I} \%$ dried yeast, I $\%$ sodium chloride and $\mathrm{I} \%$ stabilized vitamin $\mathrm{A}$ and D supplement. Of diet $4 \mathrm{I} \mathrm{B}$ approximately $60 \%$ was carbohydrate, predominantly as starch. The theoretical digestible protein content was $13.6 \%$ (Bruce \& Parkes, 1949).

In addition to the diets described, each subgroup of five rats was given weekly $20 \mathrm{~g}$ cabbage, $20 \mathrm{~g}$ carrot and $100 \mathrm{ml}$ cow's milk fortified with $100 \mathrm{mg}$ of vitamin B mixture (Greenberg et al. 1950).

The diets were offered $a d$ lib., and the food consumption of each subgroup of five rats was recorded weekly. Each rat was weighed weekly during the experimental period of 26 weeks.

Terminal studies. At the end of the experiment, samples of blood were collected from the lateral caudal vein of each rat. The animals were then killed; the measurements recorded were (I) length of body from tip of nose to tail-head and body girth immediately posterior to front legs; (2) weight of heart, kidneys, liver and spleen; (3) drymatter, fat and protein $(\mathrm{N} \times 6.25)$ contents of the liver; (4) dry-matter and fat contents of the carcass after removal of the liver.

Analytical methods. The dry-matter contents of the carcass and liver were determined by drying to constant weight in an oven at $100 \pm 2^{\circ}$; carcass and liver fat by Soxhlet extraction with light petroleum; nitrogen content of the liver by the macroKjeldahl method with a copper sulphate-selenium catalyst. Plasma cholesterol content was determined by the method of Sackett (1925). 


\section{RESULTS}

Statistical analyses. The twenty rats on each treatment were housed in cages (subgroups) of five. The analyses of variance were carried out on the cage means, and the standard errors in Tables 2, 3 and 4 are therefore based on between-cage variability. Every treatment was compared with every other one, and the probability levels of significance, in the comparison of treatments, which were obtained by using the $t$ test, may therefore be very slightly exaggerated. The smallness of this effect may, however, be seen from the comparison between $t(5 \%$ on $\mathrm{I} 2 \mathrm{df})=2 \cdot 18$ and Duncan's (1955) multiple range statistic $(5 \%, \mathrm{I} 2 \mathrm{df}$, five groups $)=2 \cdot 38$.

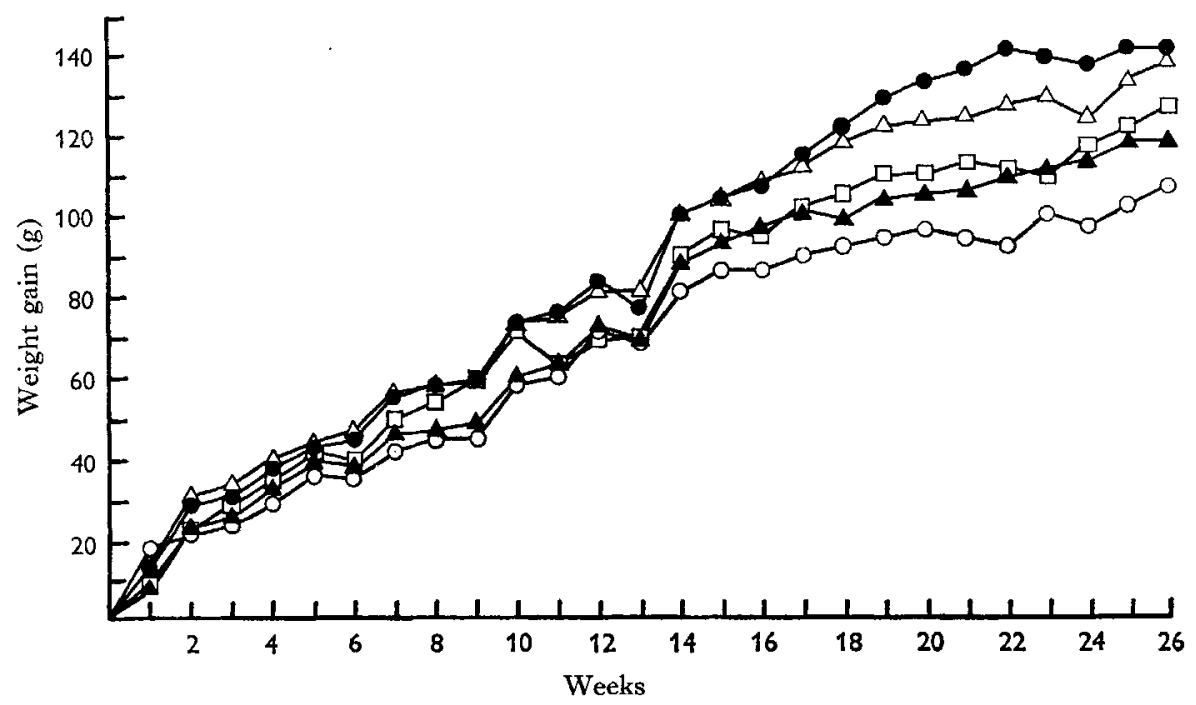

Fig. I. Weight gains of rats, initially I I months of age, given dextrose $(0-0)$, liquid glucose $(\bullet-\bullet)$, sucrose $(\Delta-\Delta)$, or fructose $(\Delta-\Delta)$ at an approximate dietary concentration of $80 \%$ and of those given a standard laboratory diet (diet 41 B, Bruce \& Parkes, 1949, I956) (口- $\square$ ).

Food consumption. The amounts of food eaten, excluding the weekly supplement of cabbage, carrot and milk, are given in Table 2 . About $7 \%$ less of the sucrose diet was eaten than of the dextrose or liquid glucose diets. More of diet $4 \mathrm{I} B$ was eaten than of any of the other diets.

Body-weight. The results are given in Table 2 and Fig. $r$. The mean body-weights of rats on all treatments increased steadily throughout the experimental period. At termination ( 26 weeks), rats given the dextrose diet had increased significantly less in weight than those given the diets containing liquid glucose (0.00I $<P<0.01)$ or sucrose $(0.01<P<0.05)$. Rats given the diet containing fructose also appeared to have gained less weight than those given the diets containing liquid glucose or sucrose, but the difference just lacked significance at the $5 \%$ level. The mean weight increase of rats given diet $4 \mathrm{I} \mathrm{B}$ was intermediate between those of the animals given the diets containing liquid glucose or sucrose and those given the diets containing dextrose or fructose. 


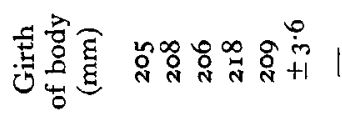

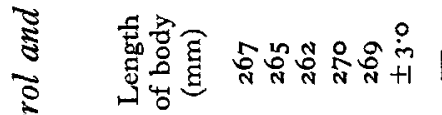

รั)

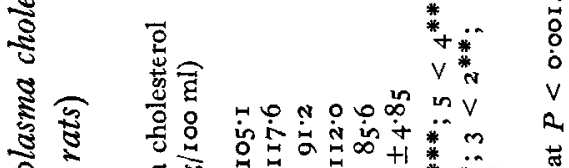

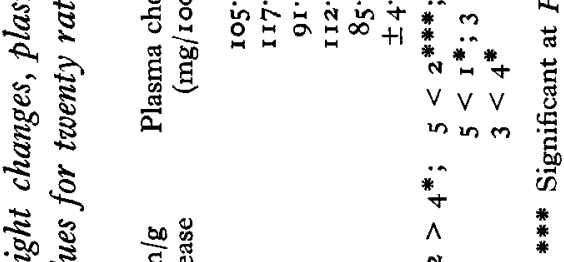

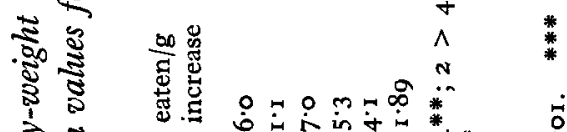

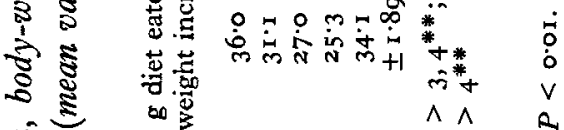

की $\hat{A}$ in $q$

(3)

害

\&

亏

ษั

క

s.

क्षे

है

.

के

芯

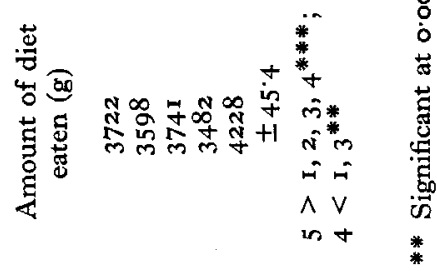

总

.

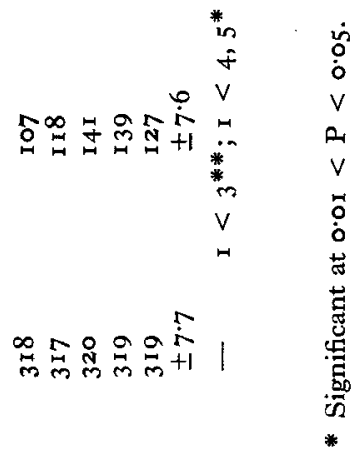

22

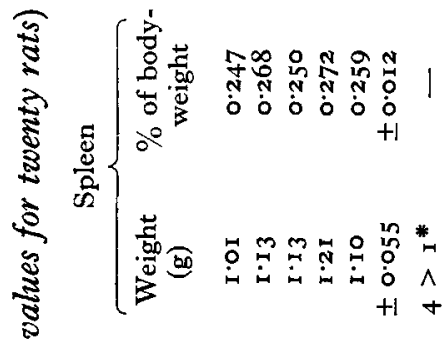

部

蛋

-

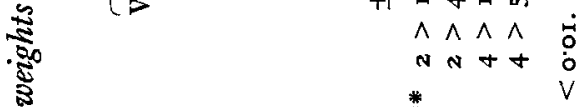

है

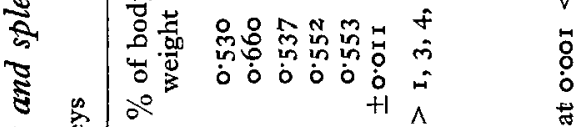

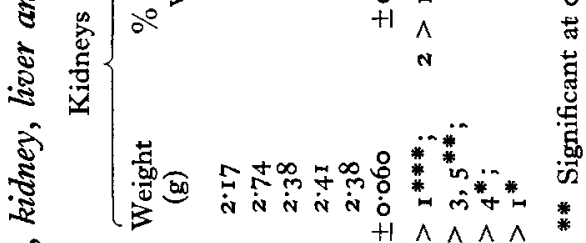

药

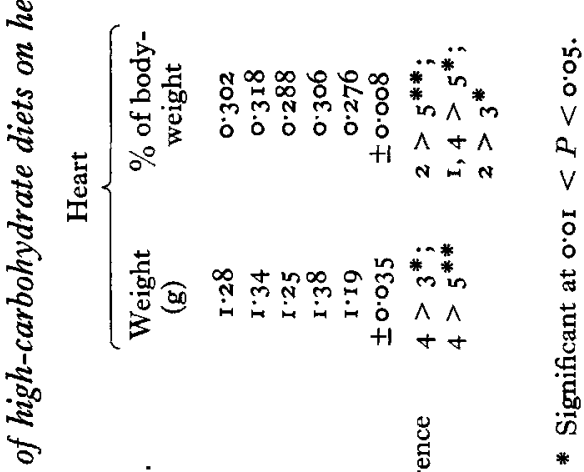

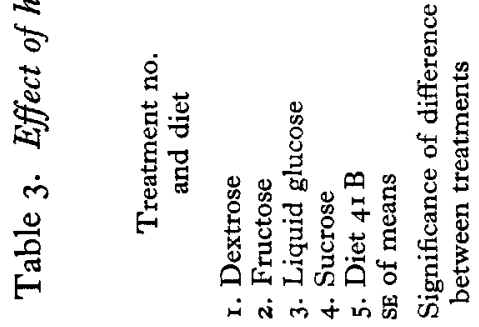

Nutr. 20, 2 
The amounts of food eaten per unit increase in body-weight are also given in Table 2. Considerably more of the diets containing dextrose or fructose was necessary for a given weight increase than of those containing liquid glucose or sucrose. This difference was not associated with a lower food intake of rats receiving dextrose or fructose.

Carcass measurements. The results are given in Table 2. There were little or no between-treatment differences in the lengths or girths of the bodies.

Plasma cholesterol. The results are given in Table 2. If the values observed for the rats given diet $4 \mathrm{IB}$ are considered as normal, then on all the high-carbohydrate diets, except that containing liquid glucose, there was an elevation of the plasma cholesterol.

Organ weights. The weights of heart, kidneys, liver and spleen are given in Table 3 . To allow for the effect of between-treatment differences in body-weight, the weights have also been calculated as percentages of body-weight. If the organ weights of rats on diet $4 \mathrm{I} \mathrm{B}$ are taken as normal values, the conclusions to be drawn are

$$
\begin{gathered}
\text { Diet } \\
\text { containing }
\end{gathered}
$$

Liquid glucose

Dextrose

Sucrose

Fructose

\section{Comparison with normal}

No difference in weight of any organ

Heart weights greater

Heart and liver weights greater

Heart, kidney and liver weights greater

The rats given the diet containing fructose had heavier kidneys and livers than those on any other treatment and greater heart weights than those given the diet containing liquid glucose.

Table 4. Effect of high-carbohydrate diets on dry matter, fat and protein contents of the carcasses and livers of adult male rats (mean values for twenty rats)

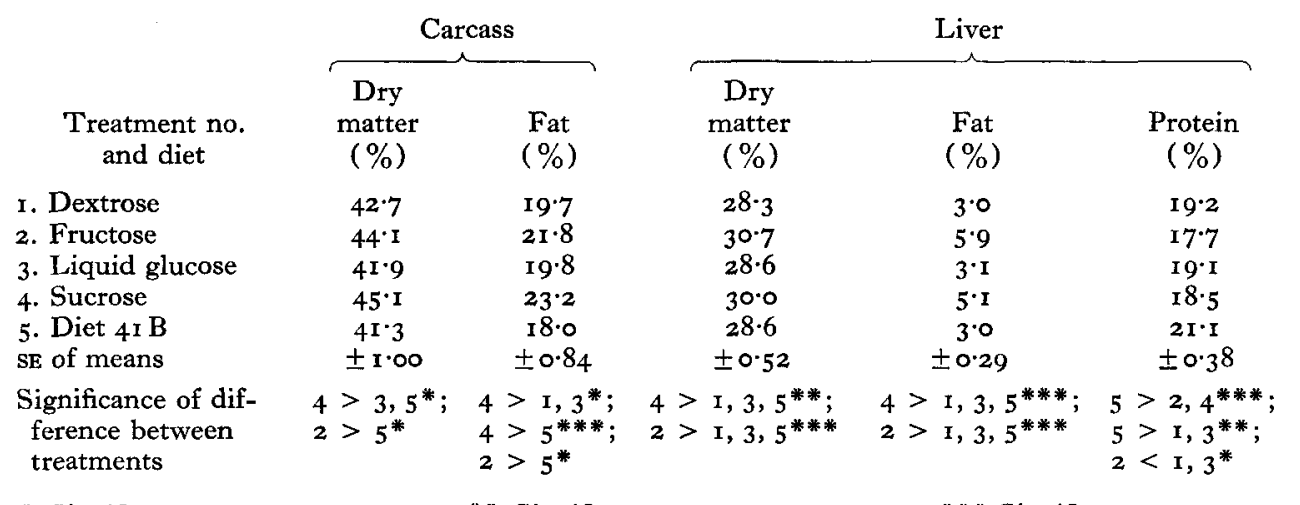

* Significant at $0.01<P<0.05$. ** Significant at $0.001<P<0.01$. *** Significant at $P<0.001$.

Carcass and liver composition. Carcass dry matter and fat and liver dry matter, fat and protein contents are given in Table 4 . Compared with the values obtained with rats given diet $4 \mathrm{I}$ B neither dextrose nor liquid glucose had any significant effect on the fat contents of either the carcasses or the livers. In contrast, sucrose and fructose led to higher fat contents in both. 
Dry-matter contents of both carcasses and livers followed substantially the same pattern as fat contents.

The protein contents of the livers of all rats given the high-carbohydrate diets were depressed compared with those of the rats given diet $4 \mathrm{I} B$. The difference was greatest with the diets containing fructose and sucrose.

\section{DISCUSSION}

The experiments reported here provide further evidence that in the rat qualitative differences in dietary carbohydrate can affect lipid metabolism, body composition and organ weights. In this study the effects were enhanced by diets containing over $80 \%$ of the test carbohydrate and, we believe, by the use of mature rats (nearly I year old), which appear to be more suitable for some types of dietary studies than the young, actively growing animals commonly employed.

More of diet 4I B was eaten than of any of the high-carbohydrate diets, but only with the dextrose group was the body-weight gain significantly lower. The sucrose group ate less than the dextrose and liquid glucose groups, but the dextrose group gained less weight than either. Conversely, sucrose and liquid glucose produced a greater weight increase per unit weight of diet eaten than did dextrose. The precise significance of these interrelationships remains to be elucidated. It seems probable from the work of Wiener, Yoshida \& Harper (1963) that in the rat the osmotic effects of different carbohydrates in the gut may play a part in determining food intake and utilization of protein.

Compared with the values for rats on diet $4 \mathbf{I}$ B, the plasma cholesterol levels in our (male) rats were increased by all the diets except that containing liquid glucose. Liquid glucose is a partial starch hydrolysate and, although the argument cannot be pressed too far (Macdonald, 1964), within limits our results may be compared to those of Macdonald (1965). He found that in men, but not in young women, the level of serum cholesterol rose when a high-sucrose diet was given. When starch replaced sucrose in the diets, the cholesterol level fell in both groups. Our observations are also consistent with those of Winitz, Graff \& Seedman (1964), who observed a sharp rise in serum cholesterol levels in men on a diet in which dextrose as the sole carbohydrate was replaced by $25 \%$ sucrose. In our experiments the effect on plasma cholesterol was greatest with fructose, less marked with sucrose and least with dextrose.

A somewhat similar gradation can be seen in the effects of the diets on heart, kidney and liver weights. All three organs were heavier in the rats fed on the diet containing fructose than in those fed on diet $4 \mathrm{I} B$, and the magnitude of the effect on kidneys and liver was also greater than with the other sugars. With sucrose, only heart and liver weights were increased and with dextrose heart weights alone. Only with liquid glucose were the organ weights unchanged compared to those with diet $4 \mathrm{I} B$. Some of the increases in organ weight that occurred with fructose and sucrose would have been large enough to arouse suspicion if observed in acute toxicity tests, where such changes are among the criteria employed.

As compared with values found with diet $4 \mathrm{IB}$, carcass and liver fat were both 
increased by sucrose and fructose but not by dextrose and liquid glucose. This finding adds to the evidence provided by other investigators (see Macdonald, 1964), which tends to suggest that more fat may be formed with dietary sucrose than with starch or carbohydrates derived from starch. Nearly $5^{\circ}$ years ago Higgins (1916) obtained evidence from a study of changes in the respiratory quotient in man that fructose, and hence sucrose, 'shows a tendency or preference to change into fat in the body' as compared with dextrose.

The implications of modification of liver fat contents by dietary carbohydrate are wide. Thus Best, Hartroft, Lucas \& Ridout (1949) found that liver fat deposition and the incidence of hepatic fibrosis in the rat were more marked with sucrose than with ethanol in diets in which choline was considered to be limiting. Macdonald (1962b) found that in adult rabbits dietary sucrose was associated with more liver lipid than was liquid glucose and the latter with more lipid than was starch. Earlier he had suggested (Macdonald, 1962a) that sucrose may influence the metabolism of unsaturated fatty acid and that this might be the mechanism operating in Yemenite Jews in Israel, in whom an increased incidence of ischaemic heart disease has been associated with higher sucrose consumption compared with those resident in the Yemen (Cohen, Bavly \& Poznanski, I96I). Cohen \& Teitelbaum (1964) have reported that impaired glucose tolerance accompanied by increased liver fat can be developed in rats by substituting sucrose for starch in the diet.

Carroll (1964) found that, with a diet containing about $6 \mathrm{r} \%$ of the test sugar, the substitution of fructose for dextrose resulted in the accumulation of less fat in the livers of weanling rats given $15 \%$ maize oil, but more in the livers of those given $15 \%$ hydrogenated coconut oil. These findings emphasize the complexity of interrelationships between carbohydrate and fat, but were observed at a much higher level of dietary fat than we have used. In assessing such interrelationships, the fact that in man more pyruvate accumulates in the blood after taking sucrose or fructose than after taking liquid glucose or dextrose (Dodds, Miller \& Rose, I 960; Leahy, Noel, Street \& Worden, I96I) may be relevant. This key intermediate can be regarded as forming a link between fat, amino acid and carbohydrate metabolism (Dodds et al. 1960).

On all the high-carbohydrate diets, liver protein was lower than on $\operatorname{diet} 4 \mathrm{I} B$. The difference was, however, greatest with the fructose and sucrose diets; on the fructose diet, liver protein content was significantly lower than on the diets containing liquid glucose and dextrose. The factors that determine the effect of type of carbohydrate on protein metabolism and particularly nitrogen retention are undoubtedly complex (Heard, 1964), but the possible significance of pyruvate formation in this process seems to merit further study.

We are indebted to our colleagues Dr M. Brook, Dr K. H. Harper and Dr K. W. G. Shillam for help and advice and to Mr K. R. L. Mansford for perfusing the liquid glucose samples. 


\section{REFERENCES}

Bachmann, G., Haldi, J., Wynn, W. \& Ensor, C. (1938). F. Nutr. 16, 229.

Best, C. H., Hartroft, W. S., Lucas, C. C. \& Ridout, J. H. (1949). Br. med. F. ii, roor.

British Pharmaceutical Codex (1963). London: The Pharmaceutical Press.

Bruce, H. M. \& Parkes, A. S. (r949). F. Hyg., Camb., 47, 202.

Bruce, H. M. \& Parkes, A. S. (1956). F. Anim. Techns Ass. 7, 54.

Carroll, C. (1964). F. Nutr. 82, 163.

Chang, V.-O. (r962). F. Nutr. 78, 2 I.

Cohen, A. M., Bavly, S. \& Poznanski, R. (I96r). Lancet, ii, I 399.

Cohen, A. M. \& Teitelbaum, A. (1964). Am. F. Physiol. 206, 105.

Corson, G. E. (1957). Critical Data Tables. New York: Corn Industries Research Foundation.

Dodds, C., Miller, A. L. \& Rose, C. F. M. (1960). Lancet, ii, I78.

Duncan, D. B. (1955). Biometrics, rr, I.

Feyder, S. (1935). F. Nutr. 9, 457 .

Fisher, R. B. \& Parsons, D. S. (1949). F. Physiol. 110, 36.

Greenberg, S. M., Calbert, C. E., Savage, E. E. \& Deuel, H. J. Jr. (1950). F. Nutr. 4I, 473.

Harper, A. E. \& Katayama, M. C. (1953). F. Nutr. 49, 261.

Heard, C. R. C. (1964). Proc. Nutr. Soc. 23, I10.

Higgins, H. L. (г916). Am. F. Physiol. 41, 258.

Leahy, J. S., Noel, P. R. B., Street, A. E. \& Worden, A. N. (196r). Lancet, ii, 1363.

Macdonald, I. (i962a). Lancet, i, 53.

Macdonald, I. (1962b). F. Physiol. r62, 334.

Macdonald, I. (1963). Am. F. clin. Nutr. 12, 43 I.

Macdonald, I. (1964). Proc. Nutr. Soc. 23, I 19.

Macdonald, I. (1965). Am. F. clin. Nutr. 16, $45^{8}$.

Macdonald, I. \& Braithwaite, D. M. (1964). Clin. Sci. 27, 23.

Marshall, M. W. \& Womack, M. (1954). F. Nutr. 52, 5 I.

Mitchell, H. H., Hamilton, T. S. \& Beadles, J. R. (r937). F. Nutr. 14, 435.

Monson, W. J., Dietrich, L. S. \& Elvehjem, C. A. (r950). Proc. Soc. exp. Biol. Med. 75, 256.

National Research Council (1929). International Critical Tables. Vol. 5. New York and London: McGraw-Hill Book Co. Inc.

Sackett, G. E. (1925). F. biol. Chem. 64, 203.

Wiener, R. P., Yoshida, M. \& Harper, A. E. (1963). F. Nutr. 80, 279.

Winitz, M., Graff, J. \& Seedman, D. A. (1964). Archs Biochem. Biophys. 108, 576. 